\title{
The Anconeus Muscle Free Flap: Clinical Application to Lesions on the Hand
}

\author{
Byung-Joon Jeon ${ }^{1 *}$, Seung Jun Jwa ${ }^{2 *}$, Dong Chul Lee ${ }^{2}$, Si Young Roh ${ }^{2}$, Jin Soo Kim² \\ ${ }^{1}$ Department of Plastic Surgery, Samsung Medical Center, Sungkyunkwan University School of Medicine, Seoul; ${ }^{2}$ Department of Plastic \\ Surgery, Gwangmyeong Sungae General Hospital, Gwangmyeong, Korea
}

Background It can be difficult to select an appropriate flap for various defects on the hand. Although defects of the hand usually must be covered with a skin flap, some defects require a flap with rich blood supply and adequate additive soft tissue volume. The authors present their experience with the anconeus muscle free flap in the reconstruction of various defects and the release of scar contractures of the hand.

Methods Ten patients underwent reconstruction of the finger or release of the first web space using the anconeus muscle free flap from May 1998 to October 2013. Adequate bed preparations with thorough debridement or contracture release were performed. The entire anconeus muscle, located at the elbow superficially, was harvested, with the posterior recurrent interosseous artery as a pedicle. The defects were covered with a uniformly trimmed anconeus muscle free flap. Additional debulking of the flap and skin coverage using a splitthickness skin graft were performed 3 weeks after the first operation.

Results The average flap size was $18.7 \mathrm{~cm}^{2}$ (range, 13.5-30 $\mathrm{cm}^{2}$ ). All flaps survived without significant complications. Vein grafts for overcoming a short pedicle were necessary in 4 cases.

Conclusions The anconeus muscle free flap can be considered a reliable reconstructive option for small defects on the hand or contracture release of the web space, because it has relatively consistent anatomy, provides robust blood supply within the same operative field, and leads to no functional loss at the donor site.

\section{Keywords Skeletal muscle / Free tissue flaps / Hand / Osteomyelitis}

Received: 24 Jan $2017 \bullet$ Revised: 12 Jun $2017 \bullet$ Accepted: 30 Jul 2017

pISSN: 2234-6163 • elSSN: 2234-6171 • https://doi.org/10.5999/aps.2017.44.5.420 • Arch Plast Surg 2017;44:420-427

\author{
Correspondence: Dong Chul Lee \\ Department of Plastic and \\ Reconstructive Surgery, \\ Gwangmyeong Sungae General \\ Hospital, 36 Digital-ro, Gwangmyeong \\ 14241 , Korea \\ Tel: +82-2-2680-7637 \\ Fax: +82-2-2615-7218 \\ E-mail: ophand0512@gmail.com
}

*Byung-Joon Jeon and Seung Jun Jwa contributed equally and share the first authorship.

The authors deeply appreciate $\mathrm{Dr}$. Aram Harijan for providing advice and corrections to this article.

No potential conflict of interest relevant to this article was reported.

\section{INTRODUCTION}

Optimal aesthetic and functional outcomes after the reconstruction of traumatic injuries of the hand cannot always be obtained even if the procedures are performed correctly. This is partly because the result of surgery depends on a range of factors, including the mechanism of injury, ischemic time, the degree of contamination, and soft tissue loss. Poor outcomes such as soft tis- sue defects, tendon or bone exposure, and scar contracture may occur, and the reconstructive options for these outcomes may be challenging. Serial reconstructive procedures should be carried out, and the transfer of well-vascularized tissue can be helpful for improving surgical results.

The muscle flap has not only been used to restore motor function $[1,2]$, but also to cover various defects, including complex, complicated, contaminated, or chronic wounds $[3,4]$. Muscle 
flaps can be helpful for improving wound healing because they provide robust blood supply around the lesion. The use of a muscle flap, however, should be carefully considered when a defect requires a flap. Mathes and Nahai [5] proposed a classification of the vascular anatomy of muscle, and 5 patterns of muscle circulation were noted. Type I muscles usually have 1 dominant vascular pedicle. If a type I muscle can be used as a flap without significant donor morbidity, it can be considered a valuable option for some challenging wounds requiring vigorous blood supply.

The purpose of this study was to introduce a new muscle flap, the anconeus muscle flap, which provides abundant blood supply to various hand defects and is harvested in the same operative field under only brachial plexus block.

\section{METHODS}

A retrospective chart review was performed for all patients who underwent free anconeus muscle flap transfer for hand reconstruction between May 1998 and October 2013. Patients were included in the study if they had soft tissue defects with exposed tendon or bone, osteomyelitis, or web space contracture. No exclusion criteria for this method were applied. All patients provided written informed consent. Patients' medical records were reviewed to obtain information regarding demographics, vessel characteristics, the anastomosis method, the total operative time, flap survival, associated complications, and whether any additional procedures were needed.

\section{Operative technique}

The anconeus free flaps were transferred under brachial plexus block. Patients were placed in the supine position with the elbow flexed at $90^{\circ}$ over the patient's torso. The intermuscular septum between the anconeus muscle and common extensor group was located with gentle palpation. After tracing the course of the recurrent posterior interosseous artery (RPIA) using portable Doppler imaging, a triangle was drawn on the skin over the anconeus muscle (Fig. 1). A line along the intermuscular septum connecting the lateral humeral epicondyle, the proximal ulna, and the tip of the olecranon made up the triangle. The tracing of the pedicle was sometimes difficult due to its location under the muscle masses.

A longitudinal skin incision was made along the designed line from the lateral humeral epicondyle to the proximal ulna. The skin flap was retracted laterally to expose the muscle fascia, and the fascia was incised along the intermuscular septum between the extensor carpi ulnaris and the anconeus muscle. With the anconeus muscle gently retracted towards the operator, the flap

\section{Fig. 1. Schematic presentation of the anatomy}

The recurrent posterior interosseous artery is shown at the deep surface of the anconeus muscle. 1 , profunda brachii artery; 2 , radial collateral artery; 3 , radial artery; 4, middle collateral artery; 5, posterior branch of the radial collateral artery; 6 , ulnar artery; 7 , common interosseous artery; 8 , anterior interosseous artery; 9 , posterior interosseous artery; black arrow, recurrent posterior interosseous artery.

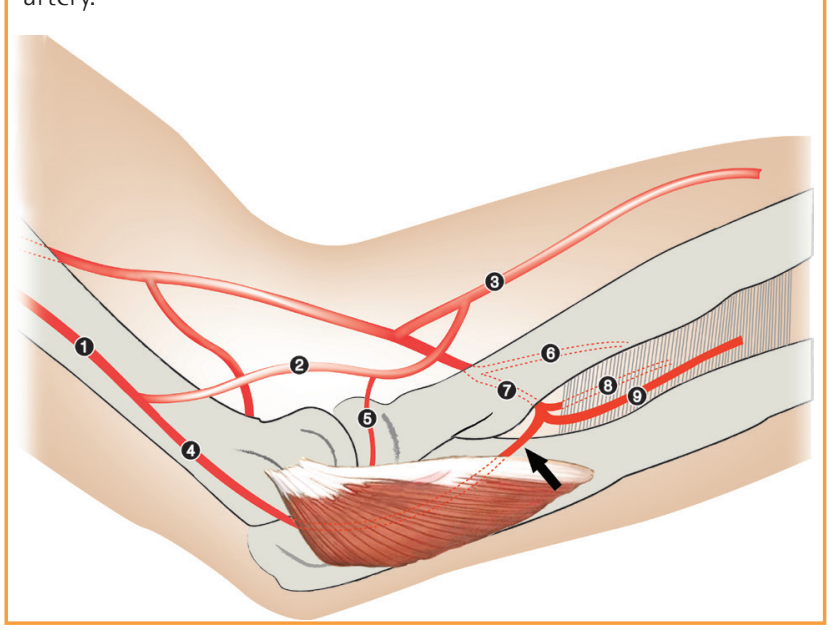

pedicle was identified where it penetrated deeply into the intermuscular septum. With isolation of this pedicle, the anconeus muscle was elevated from the lateral humeral epicondyle. At the proximal margin of the muscle, the middle collateral artery (MCA) and posterior branch of the radial collateral artery (PBRCA) were identified and ligated. The distal portion of the anconeus muscle was further dissected, and the main pedicle, usually the RPIA, was carefully dissected. The anconeus muscle was elevated at the distal attachment site to the ulna bone, and the pedicle was ligated at the penetrating point of the intermuscular septum. After meticulous hemostasis and placement of a drain, the donor site was closed primarily. A mild compressive dressing was put in place on the donor site.

The harvested muscle flap was inset into the recipient site with several stitches. The artery and venae comitantes were anastomosed with recipient vessels under an operating microscope. If the recipient digital vascular bundle was not readily accessible, the wound was extended until a suitable portion was identified proximally. If the recipient vessels were too distant to be anastomosed without tension, a distal branch of the cephalic vein was harvested and used as an interposition graft. Intraoperatively, circulation was evaluated by releasing the tourniquet, and was confirmed by sanguineous color and bleeding from the flap margin. The flap and wound were covered with an immediate or delayed split-thickness skin graft.

A skin flap could not be used for monitoring flap viability because the anconeus muscle flap does not include a septocutaneous or musculocutaneous perforator branch to the skin. As 
such, the flap was monitored using portable Doppler imaging. No anticoagulants were used.

\section{RESULTS}

The review identified 1 female patient and 9 male patients, with a mean age of 37.3 years (range, 14-61 years). Right hand injuries were observed in 2 patients, and left hand injuries were present in 8 . All the patients were right-handed.

Anconeus free flaps were used to resurface the index fingers $(n=4)$, long fingers $(n=4)$, and the first web space $(n=2)$. The injury mechanisms were amputation $(n=5)$, crushing $(n=3)$, and snake bite $(\mathrm{n}=2)$. The indications for reconstruction were tendon or bone exposure $(n=7)$, a skin and soft tissue defect $(n=1)$, and web space contracture $(n=2)$. Signs and symptoms of osteomyelitis were observed in 3 of the 7 patients with tendon or bone exposure (Table 1).

The mean length of flap pedicle was $1.6 \mathrm{~cm}$ (range, 1.0-2.1 $\mathrm{cm})$. The mean arterial diameter was approximately $1 \mathrm{~mm}$, with the respective veins having similar or slightly wider diameters. The flap vessels were anastomosed to the digital artery $(n=8)$ or to the superficial branch of the radial artery $(n=2)$, the latter of which required end-to-side anastomoses. Interposition vein grafts were required in 4 cases. The mean operative time was 179 minutes (range, 120-220 minutes). The flaps survived well with successful skin graft take in all cases, without significant complications.

With regard to the donor site, all the patients were able to move their elbow and forearm through the full range of motion and did not experience any instability or weakness of the elbow in extension. The follow-up period ranged from 2 to 9 months (mean, 5.2 months).

\section{Case 1 (Figs. 2-8)}

This 54-year-male patient was injured while using a lathe and presented with an avulsion-type amputation of the left middle finger. The amputation was at a level distal to the proximal interphalangeal joint level and was replanted. Three weeks later, the radial side of the middle phalanx became necrotic. Serial debridement of this necrotic tissue left a $3 \times 4-\mathrm{cm}$ defect with exposed bone. Despite meticulous wound care, the wound began to drain purulent discharge due to osteomyelitis of the middle phalanx. To bring the osteomyelitis under control, the defect was covered with an anconeus muscle free flap using the radial digital artery and the volar vein as a recipient vein. Due to infection and scarring, a 1-cm portion of the recipient artery was excised, and a vein graft was interposed between the healthy por-

\section{Fig. 2. Case 1: a 54-year-old male patient}

A 54-year-old male patient sustained an amputation with avulsion of the left middle finger and underwent replantation. After 3 weeks, the defect showed bony exposure with osteomyelitis on the middle phalanx and fingertip.

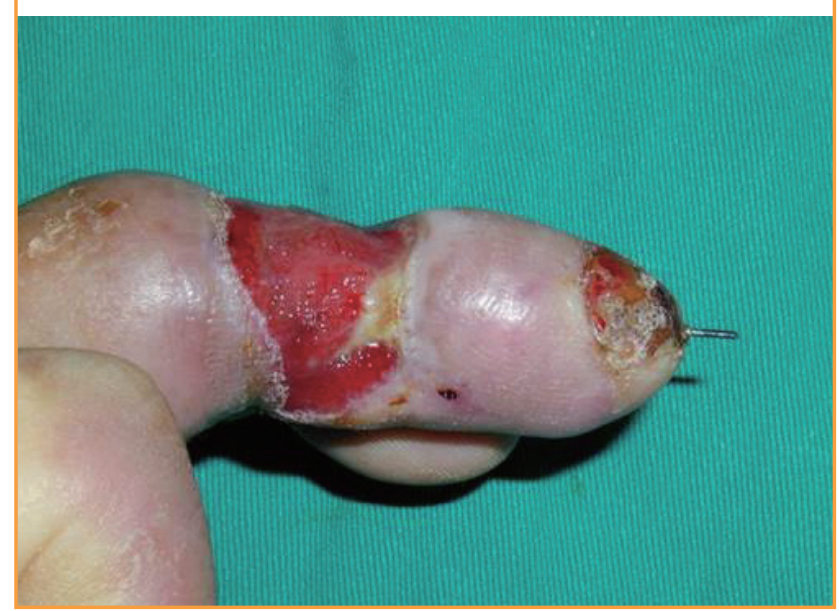

Table 1. Summary of 10 patients undergoing surgery using an anconeus muscle free flap

\begin{tabular}{|c|c|c|c|c|c|c|c|c|c|c|c|}
\hline $\begin{array}{c}\text { Case } \\
\text { no. }\end{array}$ & $\begin{array}{l}\text { Age } \\
\text { (yr) }\end{array}$ & Sex & Diagnosis & $\begin{array}{l}\text { Defect size } \\
\text { (cm) }\end{array}$ & $\begin{array}{l}\text { Cause of } \\
\text { injury }\end{array}$ & $\begin{array}{l}\text { Osteo- } \\
\text { myelitic } \\
\text { change }\end{array}$ & $\begin{array}{l}\text { Flap size } \\
\text { (cm) }\end{array}$ & $\begin{array}{l}\text { Pedicle } \\
\text { length } \\
\text { (cm) }\end{array}$ & $\begin{array}{l}\text { Vein } \\
\text { graft } \\
(\mathrm{cm})\end{array}$ & $\begin{array}{l}\text { Secondary } \\
\text { operation }\end{array}$ & $\begin{array}{l}\text { Length } \\
\text { of } \\
\text { follow- } \\
\text { up (mo) }\end{array}$ \\
\hline 1 & 54 & Male & Bone exposure, 3rd F, Lt. & $3.0 \times 4.0$ & Amputation & Yes & $4.0 \times 6.0$ & 1.8 & 1.5 & - & 6 \\
\hline 2 & 20 & Male & Soft tissue defect, 2nd F, Lt. & $2.5 \times 3.5$ & Snake bite & - & $3.0 \times 4.5$ & 1.5 & - & - & 3 \\
\hline 3 & 35 & Male & Bone exposure, 3rd F, Rt. & $3.0 \times 5.0$ & Amputation & Yes & $3.5 \times 6.0$ & 1.0 & 2.0 & - & 3 \\
\hline 4 & 32 & Male & Bone exposure, 3rd F, Lt. & $2.0 \times 3.5$ & Amputation & - & $3.5 \times 5.0$ & 2.0 & - & - & 5 \\
\hline 5 & 49 & Female & Bone exposure, 3rd F, Lt. & $2.5 \times 3.5$ & Amputation & Yes & $3.5 \times 5.0$ & 1.7 & - & - & 2 \\
\hline 6 & 38 & Male & Tendon exposure, 3rd F, Lt. & $2.0 \times 4.0$ & Crushing & - & $3.0 \times 5.0$ & 2.1 & 2.0 & Flexor tendon graft & 4 \\
\hline 7 & 61 & Male & Bone exposure, 3rd F, Lt. & $3.0 \times 5.0$ & Amputation & - & $4.0 \times 6.0$ & 1.9 & 1.8 & - & 8 \\
\hline 8 & 35 & Male & 1st web space contracture, Lt. & - & Crushing & - & $4.0 \times 7.5$ & 1.2 & - & - & 7 \\
\hline 9 & 35 & Male & 1st web space contracture, Lt. & - & Crushing & - & $4.5 \times 6.0$ & 1.4 & - & - & 5 \\
\hline 10 & 14 & Male & Tendon exposure, 3rd F, Rt. & $2.0 \times 4.0$ & Snake bite & - & $3.0 \times 5.0$ & 1.6 & - & Joint reconstruction & 9 \\
\hline
\end{tabular}




\section{Fig. 3. Surface anatomy of the anconeus muscle}

After skin incision, suprafascial plane dissection was performed. LE, lateral epicondyle of the humerus; 0 , olecranon.

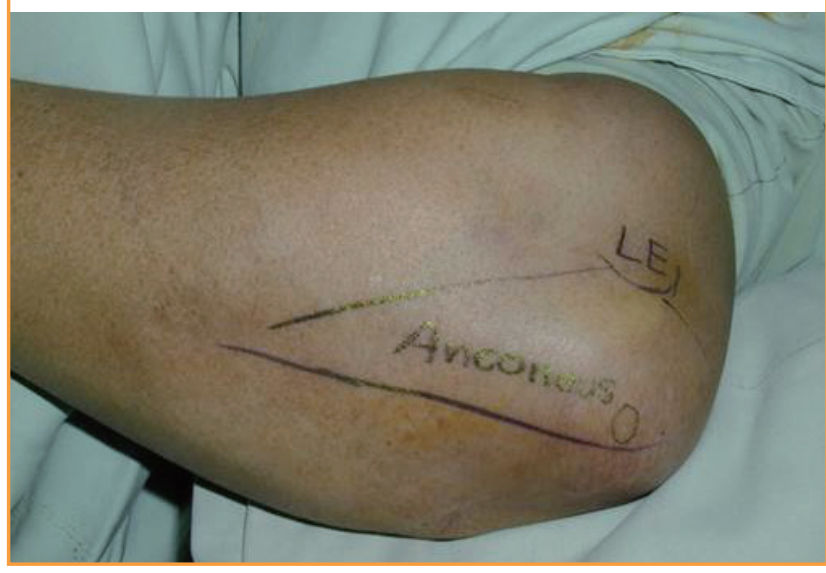

\section{Fig. 4. View during superficial dissection}

Adson forceps indicate the intermuscular septum between the anconeus muscle and common extensor group. LE, lateral epicondyle of the humerus; 0 , olecranon.

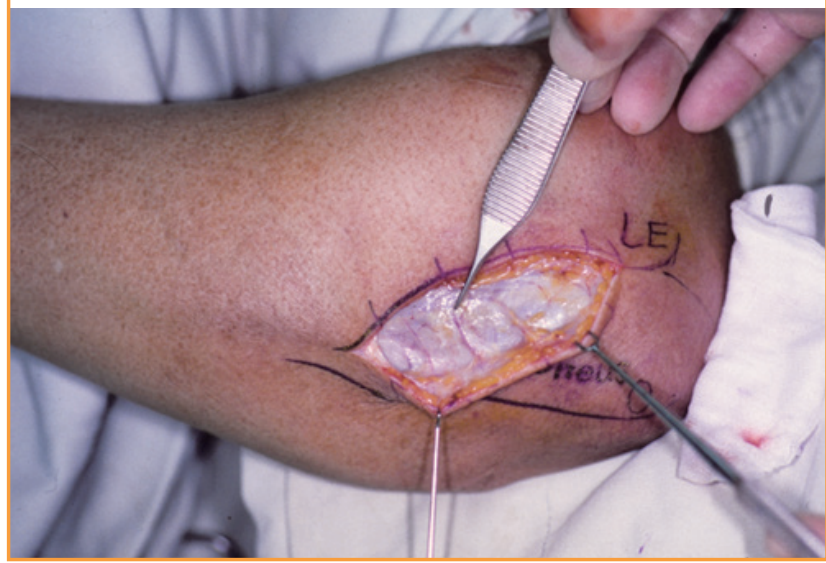

\section{Fig. 5. View during deep dissection}

The recurrent posterior interosseous artery is shown on the deep surface of the anconeus muscle. LE, lateral epicondyle of the humerus; 0 , olecranon.

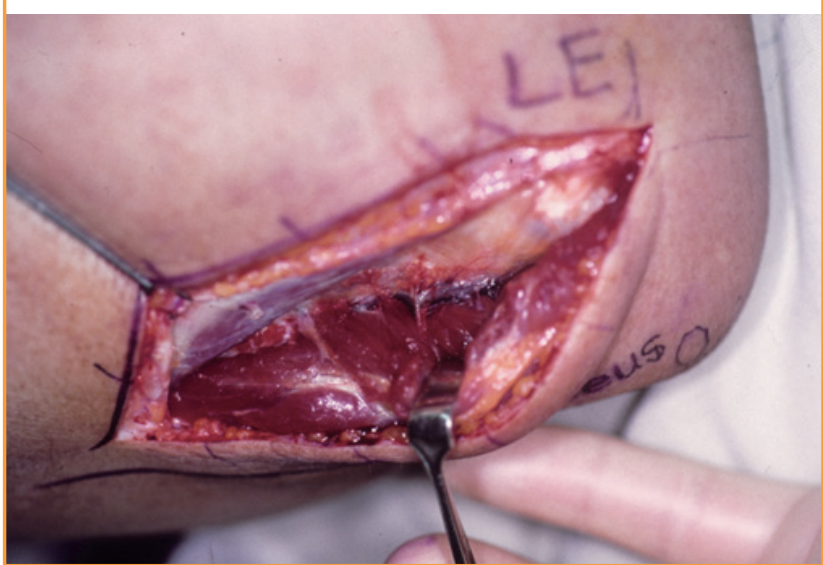

Fig. 6. The harvested flap with a vascular pedicle

A $4 \times 6$-cm anconeus muscle flap was harvested.

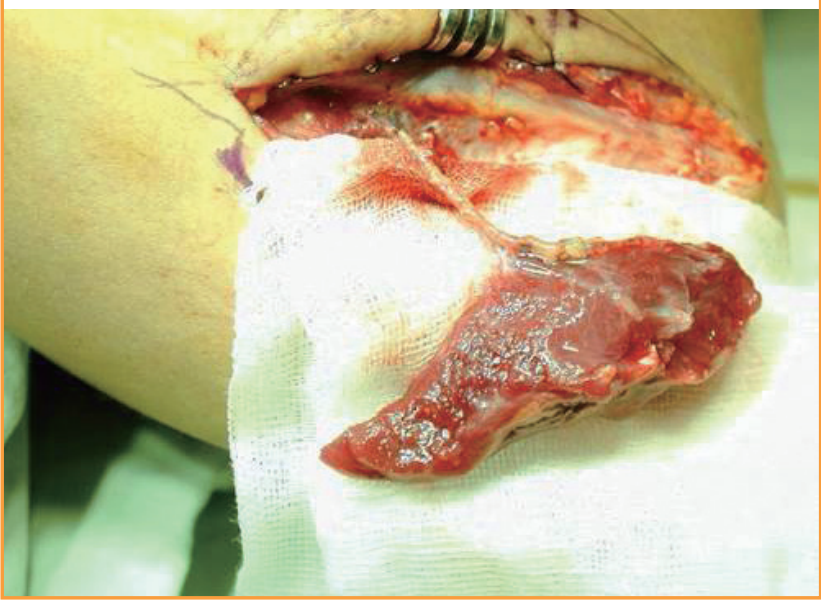

Fig. 7. Postoperative photographs

(A) Immediate postoperative view. (B) Postoperative view after 2 months. Coverage of a defect site with an anconeus muscle free flap. Debridement was performed on the fingertip. The flap survived without complication.
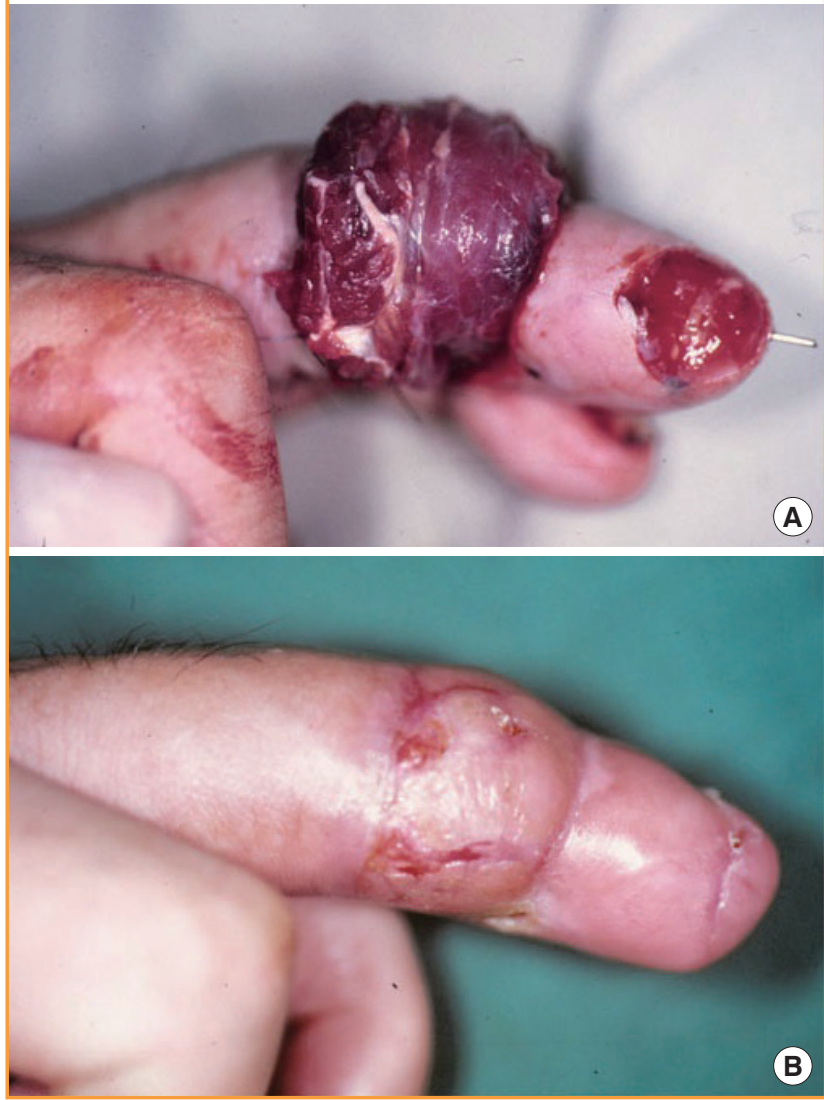

tion of the recipient artery and the donor artery. We were able to close the donor site primarily. Three weeks after the transfer operation, the muscle flap was debulked and covered with a split-thickness skin graft. The flap survived without complica- 


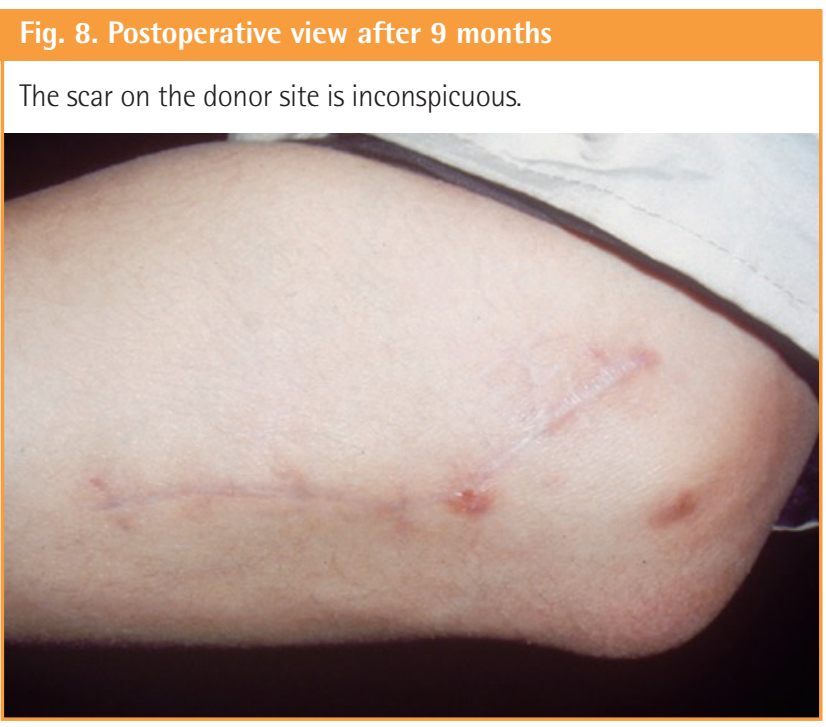

Fig. 9. Case 10: a 14-year-old male patient

A 14-year-old male patient with a skin and soft tissue defect on the right long finger.

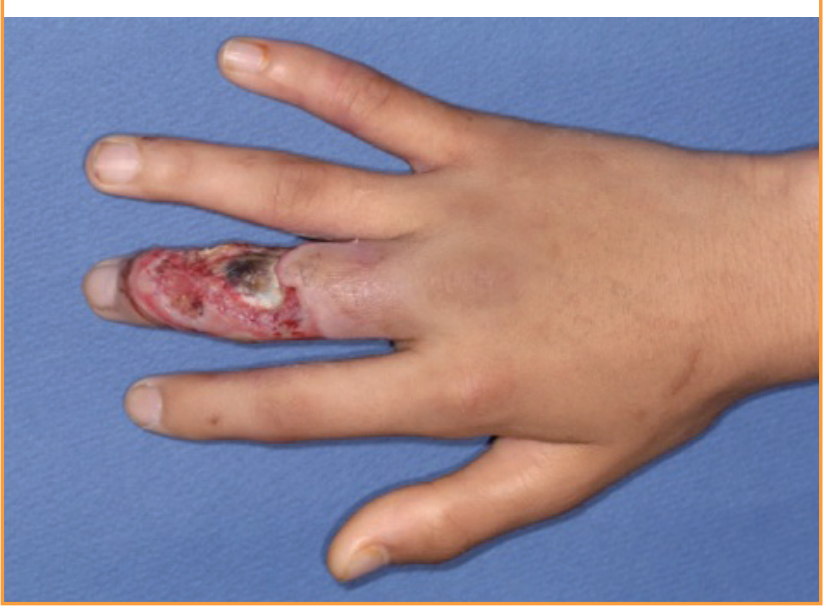

tion. No further evidence of osteomyelitis was found.

\section{Case 10 (Figs.9-15)}

The right long finger of this 14-year-old male patient was bitten by a venomous snake. Despite close observation and proper wound care for 3 weeks, the skin and soft tissue over the long finger underwent full-thickness necrosis and the patient was transferred to our institution for further management.

An anconeus muscle free flap was selected for reconstruction not only to cover the $2 \times 4-\mathrm{cm}$ defect exposing the extensor tendon but to control the persistent soft tissue infection. Under brachial plexus block, adequate debridement was done and followed by coverage with an anconeus muscle free flap. The muscle flap survived without significant complications and a splitthickness skin graft was performed 3 weeks postoperatively.

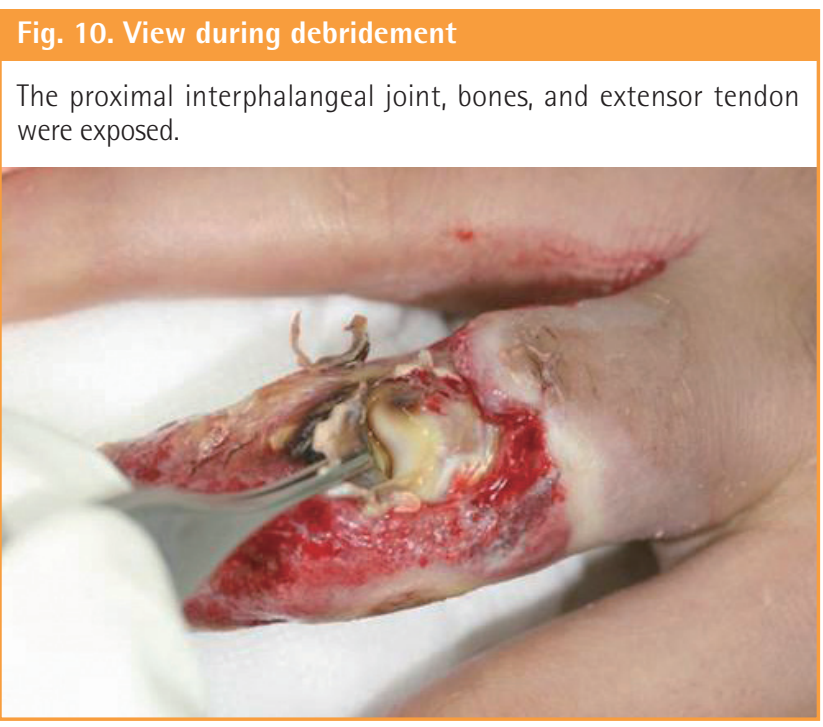

Fig. 11. The harvested flap with a vascular pedicle

A $3 \times 5-c m$ anconeus muscle flap was harvested.

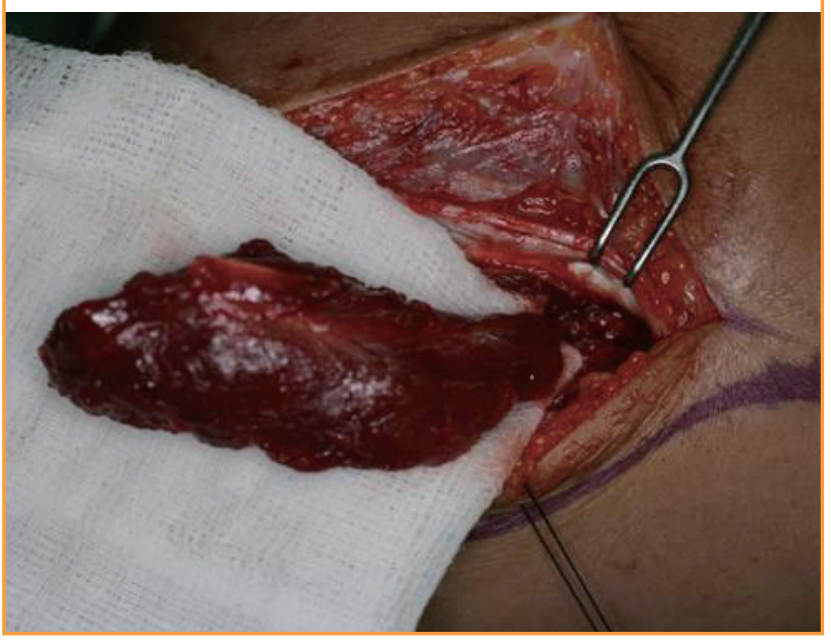

Defect coverage and infection control were successful, but the patient complained of stiffness of the proximal interphalangeal joint. The patient and his parents were concerned for the stunted growth of the finger because the injury was in his dominant hand. To address the concern of finger length, a toe-to-finger joint transfer was planned and executed 9 months after the anconeus muscle transfer. This vascularized joint was taken from the left second toe and replaced the proximal phalangeal joint of the involved finger.

No significant complications occurred at the flap site or at the donor site, and bony healing is continuing.

\section{DISCUSSION}

The anconeus muscle belongs to a group of posterior superficial 


\section{Fig. 12. Postoperative photographs}

(A) Postoperative view after 3 weeks. (B) Postoperative view after 9 months. Three weeks after the first operation, tangential excision for debulking of the flap and a split-thickness skin graft were performed. Limited motion at the proximal interphalangeal joint was observed.
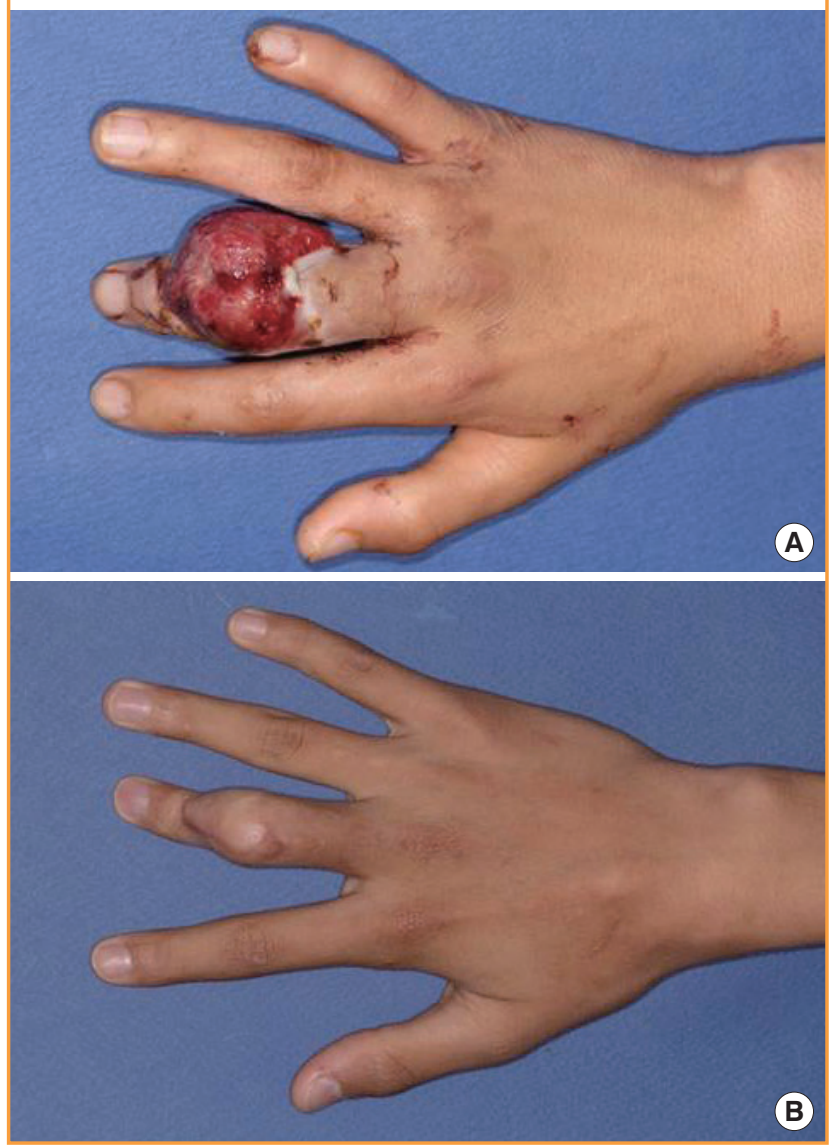

muscles in the forearm. This small, pyramid-shaped muscle assists the triceps in extension of the elbow and pronation and supination of the forearm. It stabilizes the elbow joint through its motion, and loss of this muscle is associated with minimal functional deficits $[6,7]$. The anconeus muscle is usually nourished by 3 arteries: the MCA, the PBRCA, and the RPIA. The last of these has the largest mean diameter $(1.1 \pm 0.4 \mathrm{~mm}$ or $1.9 \pm 0.2$ $\mathrm{mm}$ ) and has a consistent anatomical pattern. The artery has been reported to have a mean length of $31.3 \pm 6.9 \mathrm{~mm}$, which is adequate for microsurgical anastomosis $[8,9]$. Several publications have described the vascular anatomy of the anconeus muscle and the use of this muscle as a local flap $[8,10]$. Most recently, this muscle was considered for use as a functional free flap for thenar reconstruction, but this possibility was explored in a cadaveric study without any clinical demonstrations [9].

It is well known that complications following trauma to the tubular bones of the hand are uncommon $[11,12]$. This can partially be explained by the extensive blood supply of the phalan-

\section{Fig. 13. Design of the second toe joint free flap}

The reconstruction of the proximal interphalangeal joint of the right long finger was planned with the proximal interphalangeal joint of the left second toe as a donor site.

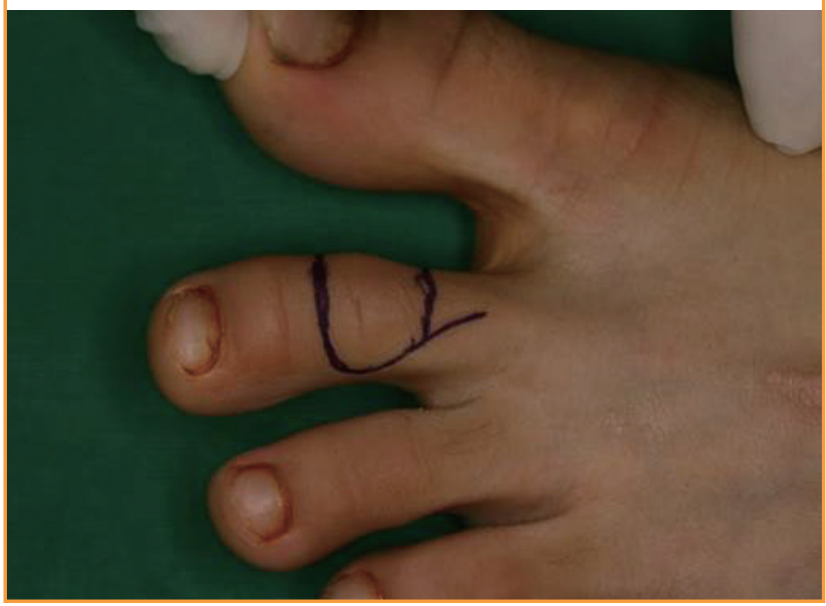

\section{Fig. 14. The harvested flap}

A $1 \times 2-c m$ second toe joint free flap was harvested.

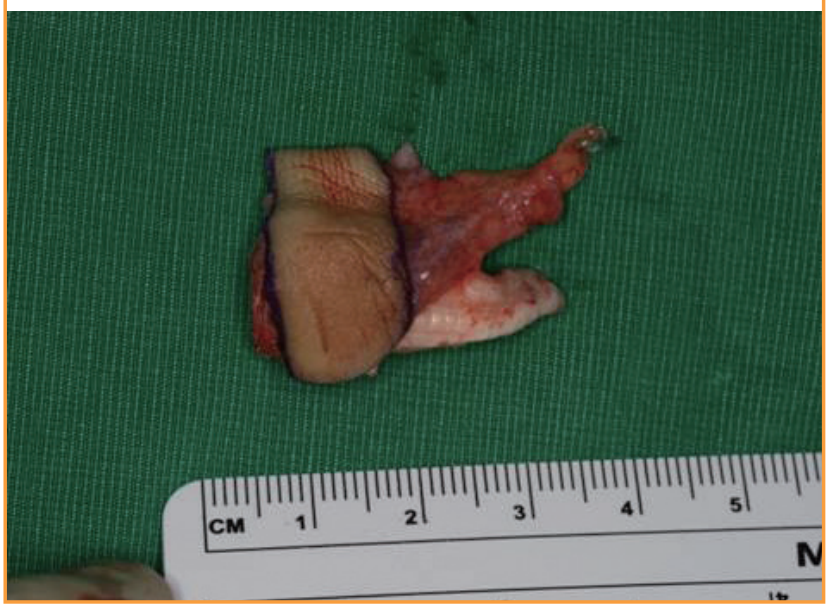

\section{Fig. 15. Postoperative view after 1 week}

The contracture of the proximal interphalangeal joint was released and straightened.

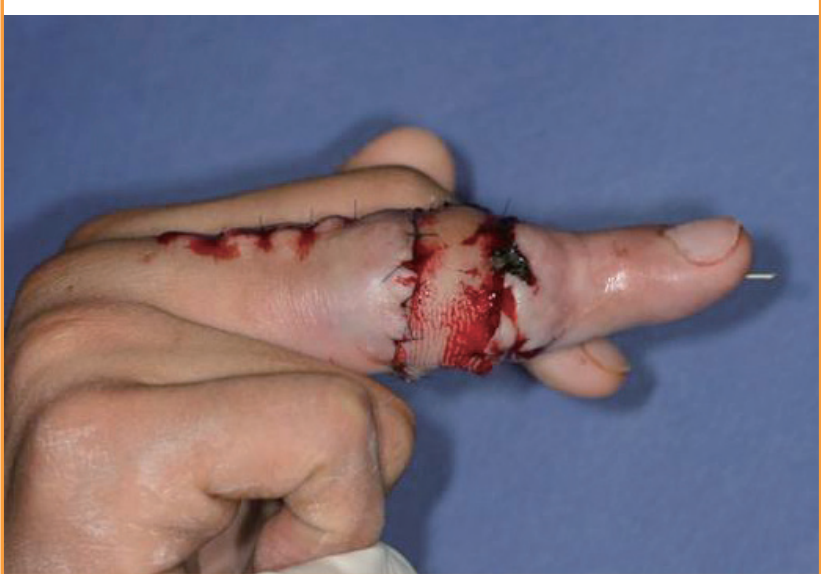


geal and metacarpal bones $[13,14]$. Conversely, any kind of trauma or insult to the hand that threatens blood supply can cause a range of wound complications, and such complications should be addressed by improving blood circulation to the lesion.

Musculocutaneous flaps were introduced first by Ger [15] and again by Orticochea [16] a decade later. Although several authors have reported the use of muscle flaps for various reconstructive purposes $[17,18]$, earlier studies did not provide strong support for the use of a muscle flap as a reliable source of blood supply for a defect or an infected dead space. However, others have discovered that muscle flaps are effective in the treatment of complex and complicated wounds, including the management of intractable osteomyelitis [19]. Several experimental studies have demonstrated that muscle flap coverage could significantly increase blood flow to devascularized bone segments in comparison with skin coverage only. Moreover, the use of a muscle flap could promote the early return of strength across an osteotomy $[4,20]$. In general, muscle flaps provide more vascularity to a defect than do fasciocutaneous flaps $[21,22]$. These findings imply that muscle flaps could be a reliable solution for chronic soft tissue infections, coverage of exposed bone, or intractable osteomyelitis [23,24].

As with all forms of reconstruction using autologous tissue, however, serious consideration should be given to donor morbidity at the location where the muscle harvest is planned, because loss of motor function and weakness of structural support have frequently been reported [25]. Although the anconeus muscle does have a relatively uncommon mechanical function, it is relatively small and causes a minimal functional deficit after flap harvest. Hence, it can be a potent treatment option for providing robust blood supply to a small wound with relatively poor circulation.

As a result of its location in the forearm, the anconeus muscle flap can be harvested within the same operative field as the injured hand, which allows the operation to proceed with a single brachial plexus block. This simplification of the operative field and anesthesia shortens the operative time and means that a positional change is not required. The elbow region is not commonly used as a donor site, and its blood vessels are usually too short to serve as vascular pedicles. However, the operative field is neither wide nor deep; therefore, the anconeus muscle free flap does not have a steep learning curve.

Using anconeus free flaps, the authors treated 5 defects with bone exposure (of which 3 were associated with osteomyelitis), 3 defects with soft tissue or tendon exposure, and 2 cases of web space contracture. Although the muscle flap was not the only factor that influenced the results, the vascularity recovered or augmented by the flap was very helpful in obtaining satisfactory outcomes. The anconeus muscle free flap fulfilled this role satisfactorily without significant donor morbidity.

\section{PATIENT CONSENT}

The patient provided written informed consent for the publication and the use of their images.

\section{REFERENCES}

1. Manktelow RT. Functioning muscle transplantation to the upper limb. Clin Plast Surg 1984;11:59-63.

2. Harii $\mathrm{K}$, Asato $\mathrm{H}$, Yoshimura $\mathrm{K}$, et al. One-stage transfer of the latissimus dorsi muscle for reanimation of a paralyzed face: a new alternative. Plast Reconstr Surg 1998;102:94151.

3. Richards RR, Schemitsch EH. Effect of muscle flap coverage on bone blood flow following devascularization of a segment of tibia: an experimental investigation in the dog.J Orthop Res 1989;7:550-8.

4. Evans GR, Francel TJ, Manson PN. Vascular prosthetic complications: success of salvage with muscle-flap reconstruction. Plast Reconstr Surg 1993;91:1294-302.

5. Mathes SJ, Nahai F. Classification of the vascular anatomy of muscles: experimental and clinical correlation. Plast Reconstr Surg 1981;67:177-87.

6. Basmajian JV, Griffin WR Jr. Function of anconeus muscle: an electromyographic study.J Bone Joint Surg Am 1972;54: $1712-4$.

7. Maselli RA, Mass DP, Distad BJ, et al. Anconeus muscle: a human muscle preparation suitable for in-vitro microelectrode studies. Muscle Nerve 1991;14:1189-92.

8. Schmidt CC, Kohut GN, Greenberg JA, et al. The anconeus muscle flap: its anatomy and clinical application. J Hand Surg Am 1999;24:359-69.

9. Ng ZY, Lee SW, Mitchell JH, et al. Functional anconeus free flap for thenar reconstruction: a cadaveric study. Hand (N Y) 2012;7:286-92.

10. Parry SW, Ward JW, Mathes SJ. Vascular anatomy of the upper extremity muscles. Plast Reconstr Surg 1988;81:358-65.

11. van Niekerk JD. Hand infections: management and results based on a new classification: a study of more than 1,000 cases. S Afr Med J 1966;40:316-9.

12. Waldvogel FA, Medoff G, Swartz MN. Osteomyelitis: a review of clinical features, therapeutic considerations and unusual aspects. N Engl J Med 1970;282:198-206.

13. Szabo RM, Spiegel JD. Infected fractures of the hand and 
wrist. Hand Clin 1988;4:477-89.

14. Ong YS, Levin LS. Hand infections. Plast Reconstr Surg 2009;124:225e-233e.

15. Ger R. The operative treatment of the advanced stasis ulcer: a preliminary communication. Am J Surg 1966;111:659-63.

16. Orticochea M. The musculo-cutaneous flap method: an immediate and heroic substitute for the method of delay. Br J Plast Surg 1972;25:106-10.

17. Prioleau WH. Muscle flap closure of cavity resulting from lung abscess. Ann Surg 1946;123:664-72.

18. Venable CS, Stuck WG. Muscle-flap transplant for the relief of painful monarticular arthritis (aseptic necrosis) of the hip. Ann Surg 1946;123:641-54.

19. Stark WJ. The use of pedicled muscle flaps in the surgical treatment of chronic osteomyelitis resulting from compound fractures. J Bone Joint Surg Am 1946;28:343-50.

20. Richards RR, McKee MD, Paitich CB, et al. A comparison of the effects of skin coverage and muscle flap coverage on the early strength of union at the site of osteotomy after devascularization of a segment of canine tibia. J Bone Joint
Surg Am 1991;73:1323-30.

21. Gothman L. Local arterial changes associated with diastasis in experimental fractures of the rabbit's tibia treated with intramedullary nailing: a microangiographic study. Acta Chir Scand 1962;123:104-10.

22. Rhinelander FW. The normal microcirculation of diaphyseal cortex and its response to fracture. J Bone Joint Surg Am 1968;50:784-800.

23. Gopal S, Giannoudis PV, Murray A, et al. The functional outcome of severe, open tibial fractures managed with early fixation and flap coverage. J Bone Joint Surg Br 2004;86:861-7.

24. Ghods M, Grabs R, Kersten C, et al. A modified free muscle transfer technique to effectively treat chronic and persistent calcaneal osteomyelitis. Ann Plast Surg 2012;68:599-605.

25. Kim H, Wiraatmadja ES, Lim SY, et al. Comparison of morbidity of donor site following pedicled muscle-sparing latissimus dorsi flap versus extended latissimus dorsi flap breast reconstruction. J Plast Reconstr Aesthet Surg 2013;66:6406. 